\title{
The Complex System Theory for the Analysis of Inter-Firm Networks: A Literature Overview and Theoretic Framework
}

\author{
Gandolfo Dominici (Corresponding author) \\ Tenured Assistant Professor of Business Management, Adjunct Professor of Marketing \\ Faculty of Economics, University of Palermo \\ E-mail: gandolfodominici@unipa.it (Note 1)
}

Gabriella Levanti

$\mathrm{PhD}$ in Business Administration, Post doc in Business Management at University of Palermo, Faculty of Economics

Received: February 26, 2011 Accepted: March 8, 2011 doi:10.5539/ibr.v4n2p31

\begin{abstract}
In this paper we discuss the body of knowledge known as complex system theory and its relevance to the analysis of inter-firm networks. We start by addressing the development of systems thinking. Through a literature overview, we point out the main elements for the development of systemic thought from its beginning, through its application in business sciences, to the birth of Complex Systems Theory (CST). With these initial annotations we provide an introduction to the concepts of the complex systems theory.

We will underscore those aspects of CST that can be useful to analyze inter-firm networks, in order to highlight the evolutionary dynamics of the networks and to clarify the logical link between the networks' structure and the cognitive processes inside the network and the firms.
\end{abstract}

In particular we highlight how CST can be an interpretative framework to connect and empower the economic, cognitive, structural and managerial aspects of network business systems.

Keywords: Inter-firm networks, Complex system Theory, Multi-level logic

\section{Introduction}

Although systemic thought roots back to ancient Greek philosophers (Pythagoras and Plato in particular), the concept of system and its working principles in modern science were first developed in the field of physics and biological sciences.

In the first decades of the $19^{\text {th }}$ century the need for a paradigm shift of scientific methodology adopted for the analysis of phenomena emerged. The weakness of the reductionist, analytical approach was that it did not contain the tools for a complete appreciation of the phenomenal reality as a whole. There was the need to observe the object of study shifting the focus from its isolated parts to the whole, thus considering relations and synergies among its elements.

In this evolution path, in the 1940s, the systemic theory of the biologist von Bertalanffy was introduced.

According to von Bertalanffy (1957, p.58): «Modern science is characterized by its ever-increasing specialization, necessitated by the enormous amount of data, the complexity of techniques and of theoretical structures within every field. This, however, has led to a breakdown of science as an integrated realm: The physicist, the biologist, the psychologist and the social scientist are, so to speak, encapsulated in a private universe, and it is difficult to get word from one cocoon to the other».

In his theory Bertalanffy defined some of the key principles of systems, among which: openness and closure, homeostasis and self-regulation, equifinality.

Soon the system theory expanded its domain to the social science and in particular to business science.

At the time in which general systems science theories were developing, another scientific approach was born: Cybernetics (Note 2). Cybernetics, as defined by Wiener (1948), is the science of control and communication in animals and machines. A remarkable contribution given by studies in the field of cybernetics was the notion of feedback as the conveyance of information about the outcome of any process or activity to its source; which is the basis of self-balancing and self-regulating feedback. Cybernetics also led to the formulation of theories which 
improved the understanding of self-organization. The characteristics of self-organization are the spontaneous emergence of new structures and new varieties of behavior in open systems that are not in equilibrium (Capra, 1996).

In Italy, the first to conceive the enterprise as a system was Gino Zappa (founder of the Italian business science school) in his book "Le produzioni nell'economia delle imprese" published in 1957. According to Zappa, the firm is a unified entity emerging from relations and interrelations linking its constitutive elements, in other words the firm is a system.

In 1972 Anthony Stafford Beer in his book: "Brain of the firm" introduced the concept of the firm as a viable system, applying cybernetics to management and defining cybernetics as the science of effective organization.

In the 1980s, the advances in this field of research highlighted other properties of systems like autopoiesis. Maturana \& Varela (1984) noted that openness and closure of a system have a complementary nature and that to understand this nature it is necessary to distinguish among organization and structure of the system. The system organization is the set of relations among its components, considered both from a static and dynamic point of view. These relations give to the systems its identity, when they change the system changes in a different system. On the other hand, the structure of the system is the peculiar way by which a system defined by an organization comes to existence in a determined space and time (Ceruti, 1992).

System of the same kind can have different structures, as well as the structure of a system can change according to external stimulus in order to keep the invariance of the system organization.

The closure of a system refers, indeed, to the organization of the system (operational closure), while openness refers to the structure and the system of interchange with the external environment (thermodynamic openness). As a consequence a system can be, at the same time, operationally closed and thermodynamically open (Ceruti, 1992).

Maturana \& Varela (1984) distinguish also among heteronymous and autonomous systems. Heteronymous systems change according to the external environment; in other words, in these systems, the adaption to the environment is of primary relevance for internal changes. In autonomous systems, instead, the internal changes of the system are not consequence of changes of the external environment. An autonomous system has an active role, selecting, among the stimuli coming from the environment, those which are "significant" and ignoring those which are not significant. Among those significant, the autonomous systems determines what is the significance that they have for the system and in which way the structure of the system need to be modified to adapt to them. In this way autonomous systems preserve the identity of the system, defined by the closure of its particular organization. This "conscious" adaptation is closely connected with the concept of "cognitive domain" of autonomous systems. The process of engagement between the system and the environment is called "structural coupling" and can be defined as "[...] history or recurrent interactions leading to the structural congruence between two (or more) systems" (Maturana \& Varela, 1987, p. 209). The stimuli coming from the environment are not considered "inputs", but as mere disturbance which may or may not cause a change of structure of the system. In the interaction among two systems their ontogenic dynamics are configured as mutual disturbances which are the cause of changes of systemic structure in both systems.

For these reasons, structural coupling has connotations of both coordination and co-evolution.

From these theoretical bases, the systemic and cybernetic theories evolved toward the theory of complex systems (CST).

\section{Complex Systems Theory (CST).}

A definition of complexity is given by Sherman \& Shultz (1998) from the Santa Fe Institute:

«Complexity refers to the condition of the universe which is integrated and yet too rich and varied for us to understand in simple common mechanistic or linear ways. We can understand many parts of the universe in these ways, but the larger and more intricately related phenomena can only be understood by principles and patterns not in detail. Complexity deals with the nature of emergence, innovation, learning and adaptation».

In other words a complex adaptive system is a system formed by a set of participants interacting with each other and co-evolving, continuously redefining their future situation.

In the field of Complex System Theory (CST) we can identify three main streams of research: the Santa Fe Institute perspective (Gleick, 1987; Waldrop, 1992; Kauffman, 1993); the European perspective (Prigogine \& Stengers, 1979,1984; Nicolis \& Prigogine, 1987), and another stream based on European epistemological tradition (Piaget, 1970; Morin, 1977; Bocchi \& Ceruti, 1985).

As happened with the systemic theories, the CST found several applications in busyness science (Stacey, 1995; 
McKelvey, 1997, 1999; Cohen, 1999; Anderson, 1999, Axeldrod, 1997; Axelrod \& Cohen, 2000; Dagnino, 2000, 2004).

Several authors in the field of business science (Tagliagambe \& Usai, 1994; Cohen 1999, Golinelli 2010) pointed out that the application of the principles of CST and systemic theory into business science is not simple. It is necessary to ponder the various concepts of these theories to avoid incorrect interpretations of the business phenomena observed.

Notwithstanding these considerations, if well considered, the application of these theories to business and firm organization studies gives a new perspective to the study of the firm, a new "key" to read the business' observable facts shedding the light on new aspects of the behavior of organizational structure of the firm and in particular of the behavior of firms inside business networks (Lewin, 1999)

Axelrod \& Cohen pointed out that: "One of the key benefits of Complex Adaptive Systems Approach is that it helps you see yourself in the context of a population of agents, and helps you see your actions in the context of a population of strategies" (Axelrod \& Cohen, 2000, p. 5).

As we said before, the systemic thought was born to overcome, with a holistic approach, the traditional reductionistanalytical methodology adopted to analyze complex phenomena. This approach was not considering the interactions emerging from the heterogeneous autonomous parts of the observed object. On the other hand, a pure holistic approach (as that of the first systemic theories) had its limits in describing the reality especially in the business environment. The first systemic theories were not able to highlight the specific and autonomous identity of the single part and the impact of these peculiar properties on the whole system. With the advances in systemic thought, several researchers acknowledged that holistic and reductionist approaches were not antagonist but complementary (Di Bernardo \& Rullani, 1990; Tagliagambe \& Usai, 1994; Fontana \& Ballati, 1999; Anderson, 1999; Golinelli, 2010).

The systemic approach is, indeed, the third way among holism and reductionism. It considers both the relations among parts forming the system, and the system as a whole made of interrelated parts: a cohesive but not a single object. The whole and the parts are two distinct and autonomous levels, but they coexist in the system. From the interaction between these two levels emerge the evolutionary dynamics both of the system and of its parts (Baum, 1999; McKelvey, 1999)

\section{CST in inter-firm networks.}

Some of the theoretical aspects of CST can be of great use to analyze inter-firm networks. The application of CST to inter-firm networks highlights the synergies coming from the cooperation among heterogeneous interconnected firms. Understanding the structure and the dynamics of the relations and the interactions among firms is a key step to comprehend the structure and the systemic dynamics of inter-firm networks.

To this aim some of the properties of CST are of great utility (Levanti, 2010; McCharty \& Frizelle, 2000). These properties are:

- Emergence. This property relates to the appearance of a new systemic behavior, as systemic response to environmental factors, because of the collective behavior and not of the individual behavior of each part. Some of the path and properties of networked systems come from spontaneous interactions among participating firms; they are not caused by behaviors intentionally controlled or coordinated by the management.

- Self-Organization. This property refers to the unplanned creation of augmented order, emerging from the internal dynamics of the system as learning, process variation, tuning and improvement. The interactions among process variations of the single parts, individual learning and tuning according to the reciprocal exchange of information and the consequential local improvements and adjustments affect the performance of the whole system. The inter-firm network creates endogenous process dynamics that spontaneously bring to enhance its organization (Kauffman, 1993). It constantly models itself, modifying its borders, creating and recreating its stock of knowledge and capabilities harmonizing with the external environment.

- Path dependence. The overall behavior of the network system depends on the weaving among current flows/stimuli received and the structural elements coming from the past stimuli and behaviors (Bertelè, 1994). This implies that historical contingencies have a role, influencing the structure and the behaviors of the inter-firm network (Arthur, 1989).

- Operational closure and thermodynamic openness. The inter-firm network system is autonomous. Its invariant organization makes it possible to identify the system itself, regardless of its specific structure in each space-time momentum (Bertschinger et al., 2006). The system exchanges energy with the external environment in terms of 
resources, knowledge and capabilities. From this channel the system receives the stimuli which (after a process of selection) can activate internal structural changes in order to preserve the organization closure and to guarantee the survival of the system.

- Complexity. Complexity is a multi-dimensional and multi-disciplinary concept. Smarr (1985) in a famous article on the journal "Science" claimed that it is not possible to define and to measure complexity. In spite of the fact that probably, as Smarr says, it is difficult to draw a precise and exhaustive definition of complexity, we can consider a complex system as a system with a high number of parts and of systemic states. To understand the concept of complexity, we have to consider two opposite notions: diversity and unity. Inter-firm networks are complex systems formed by a set of independent and idiosyncratic firms. These firms are complex sub-systems connected one to each other by feedback loops leading to the creation a complex organized unit. The inter-firm network system is united thanks to its organization but the single firm that compose the network are autonomous. Hence, the network system is something different than the mere sum of its parts. In the system we find emerging qualities, which are empirically evident but not logically inferable (Morin, 1985).

- Co-evolution. Each firm in the network, in order to operate its semi-autonomous strategies, has to continuously adapt to the other firms in the system and to environmental stimuli (Anderson, 1999; Lewin \& Volberda, 1999; Volberda \& Lewin, 2003). An analogy by Fontana \& Ballati, (1999, p.15) explains this concept: «From an evolutionary point of view, an adaptive organization is like a ship on the open sea that has to rebuild itself staying afloat».

The properties above imply that, in an inter-firm network system, the interactions are based upon both endogenous and exogenous stimuli. The former result from co-evolution processes activated by the interrelation among the systemic firms; the latter originate from co-evolution processes seeking coherence (both at systemic firm and at network level) with the external environment.

These ways of interrelation point out how the CST considers reality following both a holistic and a multi-level logic.

\section{Multi-level logic in CST.}

Complex adaptive systems are basically multilevel (McKelvey, 1997). In other words the interactions among different parts take place at different levels of analysis. This implies that there are other levels than the whole and the part. It is possible, indeed, to find sub-systems of several intermediate levels between the whole and the part. The number of these sub-systems depends on the finality and the subject of the analysis. In the field of research on the managerial organization matrix, Baum \& Singh (1994) focus their analysis on four levels (intra-organization, organization, population, community); also Kontopoulos (1993) finds four levels (local, semi-local, semi-global, global); while Monge \& Contractor (2003) underscore 5 levels (single actor, dyad, triad, sub-group, global). These differences are due to the fact that the complex system cannot be defined in a natural-objective way, because there are not hierarchical natural-objective relations among systems, sub-systems and supra-systems. Every system can be a sub-system and a supra-system at the same time.

Complex systems have "tangled composite" structures, inside which it is possible to outline several levels of analysis. At these levels, a number of semi-autonomous processes take place in order to improve the pay-offs of the participants. At the same time, these levels co-evolve interacting with other levels of the system. As Anderson (1999, p.223) points out: «Agents (and clusters of agents that form stable subsystems) coevolve with one another, because changes in the distribution of behaviors among agents change individual fitness functions, and such shifts in turn alter behaviors».

In order to identify the levels of analysis and to draw an exhaustive description of the inter-firm network, it is necessary to focus on the connective architecture of the organization. This architecture is formed by the set of interrelated systemic relations. In this context, relations have different degrees of force, and dyadic or multiple significance. In the network's architecture it is possible to spot different interconnected areas of strong interaction (cluster of firms) among firm-agents. These clusters of firms show emerging properties, self-organizing capabilities, a certain degree of autonomy; it can be considered a meso-system (Levanti, 2010). On the other hand, systemic firms and firms' clusters are connected by a set of weak links (both direct and indirect); this is the macro-system level.

Hence, in an inter-firm network system we can highlight three levels. These levels are distinct but complementary and coexisting. They are:

- micro-systemic: regards the single firms;

- $\quad$ meso-systemic: considers the different sets of firms connected among them with strong links (firms' clusters);

- macro-systemic: involves the whole network system. 
Each of these levels acts a different role in the inter-organization network, interacts with other levels and coevolves with them.

\section{CST as a dynamic approach to the analysis of inter-firm networks.}

CST analyzes inter-firm networks not just statically but with a dynamic approach. This theory overtakes the limit of Social Network Analysis that is to consider only the structure of the network.

In the analysis of economic systems, process based and dynamic approaches diverge from static and structural ones in consideration of the different concept of time they imply. The former are based on a Newtonian time concept, according to which time is "causally inert"; in other words, time can flow without any event happening and without any learning process taking place. The latter are founded on the "real time" concept, which implies that temporal dimension assumes causal power (O’Driscoll \& Rizzo, 1985). Economic agents (firms, clusters of firms, networks, etc.) acquire and gather experiences through action. This learning process causes an increase of the stock of knowledge and a change of the way of computing information. Economic agents modify their plans for future actions according to the new knowledge and perspectives; doing so they generate endogenous uncertainty.

This uncertainty creates inside economic processes the space necessary for "surprise". In other words the economic process is "dynamic" and goes on through trials and errors leading to the discovery of new opportunities that otherwise wouldn't be noticed. Indeed, the dynamic nature of the system is not subject to any limitation of knowledge expansion, so that, in the middle-long term, the system can grow thanks to the learning of each agent. Agents assume a pro-active role, defining and redefining the finalities of the system on the basis of their ability to foresee future events. Firm agents try, in this way, to anticipate the possible future evolutions of the system, which, at the time they formulate their expectations, are not rationally inferable by the actual circumstances (Mocciaro $\mathrm{Li}$ Destri \& Dagnino, 2005). Interactions can also self-generate spontaneously, at different systemic levels, without being planned by a central authority. The system automatically produces macro-order through micro-processes and meso-processes involving action, interaction and causal feed-back (Chiles et al., 2004).

Hence CST has a dynamic approach to organizational change (Mohr, 1982; Van de Ven \& Huber, 1990; Langley, 1999; Van de Ven \& Poole, 2002). Changes taking place at the three different systemic levels generate, and are generated by, both direct interaction among networked firms and indirect feed-back and feed-forward (Lewin \& Volberda, 1999). In other words, the complex recursive interactions coming from the interdependencies and from mutual causality among the three levels, reduce the importance of the distinction between dependant and independent variables; this because changes of each variable can be determined endogenously by changes in other variables.

On the basis of what we said, it is possible to assert that, in an inter-firm network system, the viable motion of interactions, feed-backs, feed-forwards, emergences, purposes and conflicts among firms and/or clusters of firms, defines and redefines, continuously, both the connective structure of the organization and the firm behaviors in the three systemic levels. This implies that these behaviors cannot be forecasted or deduced deterministically. The shift from a static to a dynamic paradigm leads to consider systemic complexity as a source of business opportunities for networked firms. In particular the connective architecture of the system and the strategies pursued at the three systemic levels, can enhance the efficiency, the effectiveness and the speed (synchronically and diachronically) of the inner processes of the networked firms (Levanti, 2010).

\section{Conclusions}

Our analysis pointed out the advantages of interpreting inter-firm networks according to the Complex System Theory (CST). These advantages are:

a) The overtaking of the limits of both holistic and analytic reductionist approaches. This is possible because CST adopt a logic that is, at the same time holistic and multi-level. Analyzing inter-firm network with a CST methodology it is possible to focus simultaneously both on synergies and on emerging properties. These synergies and emergencies stem at macro-systemic level from the interactions among different and idiosyncratic firms (micro-systemic level) and clusters of firms (meso-systemic level).

b) The shift from a static to a dynamic approach. The complex interactions succeeding through time, in the inter-firm network, define and redefine continuously both the network's connective structure and the individual and collective behaviors in the three systemic levels.

The limit of CST perspective is that it doesn't underscore the objectives of single firms or clusters. The CST explains the characteristics, the structures and the evolutionary paths of complex systems, but does not consider the specific nature of systems. Hence when we need to analyze a particular category of systems we need to integrate CST with other theories which are more specific regard the class of systems we have to investigate.

For this reason, in order to highlight the determinant factors underlying the behaviors of firms inside the inter-firm network, it is necessary to integrate CST with other managerial theories. Further research would be useful to 
investigate, for example, how CST can be completed by the recent advances in Knowledge Based Theory.

\section{References}

Anderson, P. (1999). Complexity Theory and Organization Science, Organization Science, 10 (3): 216-232. doi:10.1287/orsc.10.3.216.

Arthur, W. B. (1989). Competing Technologies, Increasing Returns, and Lock-in by Historical Events, Economic Journal, 99: 116-131. doi:10.2307/2234208, http://dx.doi.org/10.2307/2234208.

Axeldrod, R. (1997). The Complexity of Cooperation. N.J: Princeton University Press.

Axeldrod ,R. \& Cohen, M.D. (2000). Harnessing Complexity: Organizational Implications of a Scientific Frontier. NY: Basic Books.

Baum, J. A. C. (1999). Whole-part Coevolutionary Competition in Organizations, in Baum J. A. C. \& McKelvey B. (eds.). Variatiion in Organization Science: in Honor of Donald T. Campbell. London: SAGE, pp. 113-135.

Baum J.A.C. \& Singh J. V. (1994). Organizational Hierarchies and Evolutionary Processes: Some Reflections on a Theory of Organizational Evolution, in Baum J.A.C., Singh J. V. (eds.). Evolutionary Dynamics of Organizations, NY: Oxford University Press, pp.3-20.

Bertelè U. (1994). Sistemi di imprese e differenziali produttivi, in Dioguardi G (ed.). Sistemi di imprese. Le nuove configurazioni dell'impresa e dei mercati. Milan: Etas.

Bertschinger N., Olbrich E., Ay N. \& Jost J. (2006). Information and Closure in Systems Theory, in Explorations in the Complexity of Possible Life, Artmann S. \& Dittrich P. (eds.), Amsterdam: IOS Press.

Bocchi G. \& Ceruti M. (1985). La sfida della complessità. Milan: Feltrinelli.

Capra, F. (1996). The Web of Life. 1st Anchor Books.

Ceruti M. (1992). Presentazione: per una storia naturale della conoscenza, in Maturana H. \& Varela F., L'albero della conoscenza. Milan: Garzanti.

Chiles T. H., Meyer A. D., Hench T. J. (2004). Organizational Emergence: The Origin and Transformation of Branson, Missouri's Musical Theaters, Organization Science, 15 (5): 499-519. doi:10.1287/orsc.1040.0095, http://dx.doi.org/10.1287/orsc.1040.0095.

Cohen M.D. (1999). Commentary on the Organization Science Special Issue on Complexity, Organization Science, 10 (3): 373-376. doi:10.1287/orsc.10.3.373, http://dx.doi.org/10.1287/orsc.10.3.373.

Dagnino G. B. (2000). Conoscenza, complessità e sistemi d'imprese. Turin: Giappichelli.

Dagnino G. B. (2004). Complex Systems as Key Drivers for the Emergence of a Resource and Capability-Based Interorganizational Network", Emerge: Complexity and Organization, 6 (1-2): 61-69.

Di Bernardo B. \& Rullani E. (1990). Il management e le macchine. Teoria evolutiva dell'impresa. Bologna: Il Mulino.

Dominici G. (2008). Holonic Production System to obtain flexibility for Customer Satisfaction, Journal of Service Science and Management, 1 (3): 251-254. doi:10.4236/jssm.2008.13027, http://dx.doi.org/10.4236/jssm.2008.13027 .

Fontana W. \& Ballati S. (1999). Complexity, Complexity, $4 \quad$ (3): 14-16. doi:10.1002/(SICI)1099-0526(199901/02)4:3<14::AID-CPLX3>3.0.CO;2-O.

Forrester J. W. (1968) Principles of Systems. Cambridge, MA: Wright-Allen Press.

Gleick J. (1987). Chaos: Making a New Science. NY: Penguin.

Golinelli G.M. (2010). Viable Systems Approach (VSA). Governing business dynamics. Padua: CEDAM.

Kauffman S. A. (1993). The Origins of Order: Self-organization and Selection in Evolution. NY: Oxford University Press.

Kontopoulos K. M. (1993). The logics of Social Structure. NY: Cambridge University Press.

Langley A. (1999). Strategies for Theorizing from Process Data, Academy of Management Review, 24 (4): 691-710. doi:10.2307/259349, http://dx.doi.org/10.2307/259349 .

Levanti G. (2010). Il governo dei sistemi reticolari di imprese. Milan: FrancoAngeli.

Lewin A. Y. (1999). Application of Complexity Theory to Organization Science, Organization Science 10 (3): 215-223. doi:10.1287/orsc.10.3.215, http://dx.doi.org/10.1287/orsc.10.3.215.

Lewin A. Y. \& Volberda H. W. (1999). Prolegomena on Coevolution: A Framework for Research on Strategy and 
New Organizational Forms", Organization Science, 10 (5): 519-534. doi:10.1287/orsc.10.5.519, http://dx.doi.org/10.1287/orsc.10.5.519 .

Maturana H. \& Varela F. (1984). El Arbol del Conocimiento. Las Bases Biologicas del Entendimiento Humano. Santiago: Editorial Universitaria.

McCarthy I. P., Rakotobe-Joel T., Frizelle G. (2000). Complex systems theory: implications and promises for manufacturing organizations, International Journal of Manufacturing Technology and Management, 2, (1-7): 559-579.

McKelvey B. (1997). Quasi-natural Organization Science, Organization Science, 8 (4): 352-380. doi:10.1287/orsc.8.4.351, http://dx.doi.org/10.1287/orsc.8.4.351

McKelvey B. (1999). Avoiding Complexity Catastrophe in Coevolutionary Pockets: Strategies of Rugged Landscapes, Organization Science, 10 (3): 294-321. doi:10.1287/orsc.10.3.294.

Mocciaro Li Destri A. \& Dagnino G. B. (2005). The Resource-Based Firm Between Value Creation and Value Appropriation", Advances in Strategic Management, 22:153-188. doi:10.1016/S0742-3322(05)22006-5, http://dx.doi.org/10.1016/S0742-3322(05)22006-5 .

Mohr L. B. (1982). Explaining Organizational Behavior. San Francisco: Jossey-Bass.

Monge P. R. \& Contractor N. S. (2003). Theories of Communication Networks. NY: Oxford University Press.

Morin E. (1985). Le vie della complessità, in Bocchi G \& Ceruti M. (eds.), La sfida della complessità. Milan: Feltrinelli.

Morin E. (1977). La Méthode, tome I: la nature de la nature. Paris : Editions du Seuil.

Nicolis G. \& Prigogine I. (1987). Exploring Complexity. An Introduction. Munich: Piper.

O’Driscoll G.P. \& Rizzo M. J. (1985). The Economics of Time and Ignorance. Oxford: Basil Blackwell.

Prigogine I., Stengers I., 1979, La Nouvelle Alliance. Metamorphose de la Science, Gallimard, Paris.

Prigogine I. \& Stengers I. (1984). Order Out of Chaos: Man's New Dialogue with Nature. NY: Bantam Books.

Sherman, H. \& Shultz, R. (1998). Open Boundaries: Creating Business Innovation through Complexity. MA: Perseus Books.

Smarr L. (1985). An approach to complexity: numerical computations. Science, 228:403-408. doi:10.1126/science.228.4698.403 PMid:17746870, http://dx.doi.org/10.1126/science.228.4698.403 .

Stacey R. D. (1995). The Science of Complexity: An Alternative Perspective for Strategic Changed Processes", Strategic Management Journal, 16: 477-495. doi:10.1002/smj.4250160606, http://dx.doi.org/10.1002/smj.4250160606 .

Stafford Beer A. (1972). Brain of the Firm. London: The Penguin Press.

Tagliagambe S \& Usai G. (1994). L’impresa tra ipotesi, miti e realtà. Milan: ISEDI.

Van de Ven A. H. \& Huber G. P. (1990). Longitudinal Field Research Methods for Studying Processes of Organizational Change", Organization Science, 1:213-219. doi:10.1287/orsc.1.3.213

Van de Ven A. H. \& Poole m. S. (2002). Field Research Methods, in Baum J. A. C. (ed.), Companion to organizations. MA: Blackwell.

Vicari S. (1991). L’impresa vivente. Itinerario di una diversa concezione. Milan: Etas.

Volberda H. W. \& Lewin A. Y. (2003). Co-evolutionary Dynamics Within and Between Firms: From Evolution to Co-evolution, Journal of Management Studies, 40 (8): 2111-2136. doi:10.1046/j.1467-6486.2003.00414.x, http://dx.doi.org/10.1046/j.1467-6486.2003.00414.x

Von Bertalanffy L. (1957). General system Theory, in Life, Language, Law: Essays in Honor of Arthur F. Bentley. Taylor R. W., (ed.). Yellow Springs, OH: Antioch Press.

Waldrop W. M. (1992). Complexity: The Emerging Science at the Edge of Order and Chaos, NY: Touchstone.

Wiener, N. (1948). Cybernetics or Control and Communications in the Animal and theMachine, Cambridge, Massachusetts: Technology Press.

\section{Notes}

Note 1. According to Italian regulation on scientific publishing we declare that prof. Gandolfo Dominici contributed mainly to paragraph 1, 2 and 3 and Dr. Gabriella Levanti contributed mainly to paragraphs 4,5 and 6.

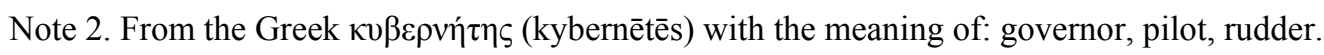

